\title{
OPTIMASI PROSES PENGUKURAN DIMENSI DAN DEFECT UBIN KERAMIK MENGGUNAKAN PENGOLAHAN CITRA DIGITAL DAN FULL FACTORIAL DESIGN
}

\author{
Denny Sukma Eka Atmaja \\ Pascasarjana Teknik Industri \\ Fakultas Teknik Universitas Gadjah Mada \\ Email: dennysukma@gmail.com \\ Muhammad Kusumawan Herliansyah \\ Pascasarjana Teknik Industri \\ Fakultas Teknik Universitas Gadjah Mada \\ Email: herliansyah@ugm.ac.id
}

\begin{abstract}
Theinspection process of surface quality of ceramic tile could be done by using image processing technique through the optimization by using Center for Ceramics's parameteron Indonesian National Standard (SNI) ISO 10545. This research will analyze from light intensities (level 300lx,600lx, and 900lx), and camera distances (50cm, 75cm and $100 \mathrm{~cm}$ ), with three times replication using full factorial design. This research uses Matlab 2009a software to identify area and defect on dry spots ceramic tile's surface. The result obtained from this research is there were significant influencing factors: light intensity, and camera distance, as well as the interaction of these factors towards the error rate percentage of measuring areaand defect on ceramic tile's surface. The smallest error rate value from measuring tile's surface and diameter of dry spots with light intensity of 300lx and camera distance of $50 \mathrm{~cm}$ had been obtained the error rate value for each measurement about $0.0675 \%$ and $2.30 \%$, with combination of grayscale value for the error rate measurements of tile's surface and diameter of dry spots were $0.2989 x 0.1140$ $x R+G+0.5870 \times B$. Based on the correlation coefficient value between light intensity, camera distance towards the error rate of measuring areaand defect on tile's surface, each of them was obtained correlation coefficient value of camera distance with error rate had 0.518 and 0.516 , which meant a strong correlation. The positive correlation coefficient value showed a unidirectional relationship of two variables, where the rise of one variable would cause the rise of another variable and the decline of one variable would cause the decline of another variable.
\end{abstract}

Keywords: Image processing technique; Full factorial design; Design of experiment; Binary scale; Ceramic tile

\begin{abstract}
ABSTRAK
Proses pemeriksaan kualitas permukaan ubin keramik dapat dilakukan dengan memanfaatkan teknik pengolahan citra melalui optimasi menggunakan parameter dari Balai Besar Keramik yang mengacu pada SNI ISO 10545. Penelitian ini akan melakukan analisis dari faktor intensitas cahaya (level 300 lx, 600 lx, dan 900 lx) dan jarak kamera $(50 \mathrm{~cm}, 75 \mathrm{~cm}$, dan $100 \mathrm{~cm})$, dengan replikasi sebanyak 3 kali dengan menggunakan full factorial design. Penelitian ini menggunakan aplikasi yang telah dibuat dengan menggunakan Matlab 2009a untuk mengidentifikasi luas dan cacat permukaan ubin jenis dry spots. Hasil yang diperoleh dari penelitian ini mendapati dua faktor yang berpengaruh signifikan yaitu intensitas cahaya dan jarak kamera, maupun interaksi dari kedua faktor terhadap presentase tingkat kesalahan pengukuran luas dan cacat pada ubin keramik. Tingkat error terkecil dari pengukuran luas permukaan ubin dan pengukuran diameter dry spots pada intensitas cahaya $300 \mathrm{~lx}$ dengan jarak $50 \mathrm{~cm}$ diperoleh nilai tingkat error untuk masing-masing pengukuran sebesar 0,0675\% dan 2,30\%, dengan kombinansi nilai grayscale untuk tingkat error pengukuran luas permukaan dan pengukuran diameter dry spots adalah $0,2989 \times R+0,1140 \times G+0,5870 \times$ B. Berdasarkan nilai koefisien korelasi antara intensitas cahaya, jarak
\end{abstract}


kamera terhadap tingkat error pengukuran luas ubin dan cacat dry spots, masing-masing diperoleh nilai koefisien korelasi jarak kamera dengan tingkat error memiliki nilai 0,518 dan 0,516 yang berarti hubungan korelasi kuat. Koefisien korelasi positif menunjukkan hubungan yang searah dari dua variabel, di mana kenaikan satu variabel akan menyebabkan kenaikan variabel yang lain dan sama halnya penurunan satu variabel akan menyebabkan penurunan variabel yang lain.

Kata Kunci: Image processing technique; Full factorial design; Design of experiment; Binary scale; Ubin keramik

\section{PENGANTAR}

Pada saat ini proses inspeksi visual terhadap kualitas ubin keramik baik yang dilakukan di Balai Besar Keramik maupun dan industri keramik di Indonesia masih dilakukan secara manual dengan penglihatan manusia. Hal ini tentu sajadapat membutuhkan proses inspeksi yang relatif lama karena adanya keterbatasan pada penglihatan manusia dan adanya perbedaan persepsi antara individu yang satu dengan yang lainnya (Elbehiery dkk, 2005). Penglihatan manusia harus secara tepat dapat melihat objek kerusakan pada permukaan ubin keramik. Secara kasat mata, seorang manusia tanpa memiliki pengetahuan yang khusus dapat membedakan keramik yang normal tanpa cacat dengan keramik yang mempunyai cacat. Biasanya meraka hanya berbekal pengalaman dan pengetahuan yang didapat sebelumnya (Elbehiery dkk 2005). Hawa panas dan kejenuhan dalam proses pemeriksaan yang monoton dapat menyebabkan ketidaktelitian dan kesalahan dalam penentuan kualitas ubin. Proses penyeleksian ini dilakukan tidak hanya seorang diri tapi bisa mencapai 2-3 orang atau lebih secara bergantian dengan tujuan untuk menjaga akurasi pada proses inspeksi. Selain itu menurut Elbehiery dkk (2005), penilaian manusia biasanya dipengaruhi oleh harapan dan pengetahuan yang dimiliki sebelumnya. Akan tetapi, proses penyeleksian yang dilakukan oleh manusia secara manual ini tetap saja dapat memperlambat proses produksi dan pengepakan keramik secara keseluruhan (Afandi dkk 2010).

Proses kontrol merupakan salah satu persoalan yang penting dalam persaiangan antara produsen industri keramik serta mempengaruhi harga dengan melihat kemurnian dari tekstur, akurasi warna, dan bentuk (Rahaman dkk 2009). Kontrol kualitas mutu permukaan keramik (surface quality) adalah salah satu parameter yang dapat diamati secara langsung baik di line produksi maupun oleh konsumen. Seiring dengan perkembangan teknologi komputer yang semakin canggih dan teknik pengolahan citra saat ini dapat diimplementasikan untuk membantu produsen dalam melakukan kontrol kualitas permukaan ubin.

Menurut Wise dkk (1990) dalam Ikrar (2004) pemanfaatan citra dalam ilmu pengetahuan telah berlangsung sejak lama dan terus berkembang sampai saat ini. Sejumlah besar data yang menggambarkan sebuah objek dan komplek dapat direpresentasikan hanya dengan visualisasi data tersebut sebagai sebuah citra. Elbehiery dkk (2005) menggunakan teknik pengolahan citra dan pengoperasian morfologikal pada proses pendeteksian cacat pada keramik. Penelitian yang dilakukan Afandi dkk (2010) mengimplementasikan teknik pencitraan dengan melakukan pengklasifikasian kualitas keramik menjadi empat kategori yakni kualitas-1, kualitas-2, kualitas-3, dan kualitas-4 dengan acuan menggunakan operasi selisih piksel putih untuk menentukan jenis kualitas keramik. Pratiwi dkk (2014) merancang sistem dengan menggunakan sensor kamera untuk pengambilan citra dan menggunakan komputer sebagai perangkat lunak untuk pemrosesan citra. Pada penelitian tersebut, pengaruh kondisi lingkungan dalam hal ini proses pencahayaan, merupakan parameter yang perlu diperhatikan karena kondisi intensitas 
cahaya dapat berubah sesuai dengan kondisi lingkungan. Terkait proses inspeksi terhadap kualitas dari ubin keramik terdapat tiga parameter yang diukur oleh beberapa mesin vision yang digunakan untuk proses inspeksi secara visual terkait kualitas ubin keramik, yaitu analisis warna, mendeteksi setiap jenis cacat pada proses manufaktur, dan mengukur kepresisian dari dimensi ubin keramik (Boukouvalas dkk, 1998).

Berdasarkan SNI ISO 10545-2:2010 mengenai prosedur inspeksi mutu permukaan keramik, jarak pengamatan dilakukan pada jarak 1 meter dengan intensitas cahaya $300 \mathrm{~lx}$ pada permukaan ubin dengan menggunakan mata telanjang. Berdasarkan acuan tersebut maka pada penelitian ini menggunakan dua hal tesebut sebagai variabel yang mempengaruhi dalam inspeksi kualitas permukaan ubin keramik. Pada penelitian ini akan dikembangkan suatu sistem visual yang lebih sederhana yang mampu digunakan untuk mengukur variabel-variabel yang mempengaruhi inspeksi kualitas permukaan ubin keramik khususnya untuk mengetahui tingkat kepresisian terhadap pengukuran luas dan defect ubin keramik jenis dry spots. Untuk mendapatkan tingkat akurasi yang tinggi atau tingkat error yang minimal dengan melakukan manipulasi variabelvariabel untuk mengetahui respon sehingga ekperimen yang dilakukan mendapatkan hasil yang valid dan objektif, maka perlu dilakukan suatu design of experiment.

\section{Image Processing}

Menurut Efford (2000) dalam Kadir dan Susanto (2013) pengolahan citra adalah istilah umum untuk berbagai teknik yang keberadaannya untuk memanipulasi dan memodifikasi citra dengan berbagai cara. Menurut Kadir dan Susanto (2013) pengolahan citra merupakan bagian penting yang mendasari berbagai aplikasi nyata, seperti pengenalan pola, penginderaan jarak jauh melalui satelit atau pesawat udara, dan machine vision. Pada pengenalan pola, pengolahan citra antara lain berperan untuk memisahkan objek dari latarbelakang secara otomatis. Selanjutnya, objek akan diproses oleh pengklasifikasi pola. Pada penelitian dengan tujuan untuk mengidentifikasi produk berdasarkan kualitasnya telah banyak dikembangkan. Elbehiery dkk (2005) menggunakan konsep image processig untuk mengidentifikasi defect pada keramik. Boukuvalas dkk (2006) berfokus pada masalah inspeksi otomatis keramik ubin menggunakan computer vision yang digunakan untuk mendeteksi berbagai jenis cacat pada jenis ubin polos dan bertekstur.

\section{Full Factorial Design}

Untuk mendapatkan hasil yang valid serta objektif dibutuhkan suatu metode yang mampu memanipulasi variabel-variabel untuk mengetahui respon yang dihasilkan, yaitu dengan menggunakan design of experiment. Penelitian yang dilakukan Baroroh (2014) terkait optimasi terhadap proses electrochemical machining dengan menggunakan 2 faktor dan 3 level dengan respon nilai material removal rate (MRR) serta menggunakan replikasi sebanyak 3 kali menggunakan pendekatan full factorial design. Pada penelitian tersebut menghasilkan kedua faktor tersebut memiliki pengaruh yang signifikan terhadap nilai MRR maupun overcut. Penelitian lainnya terkait dengan design of experiment adalah penelitian Jayabal dkk (2011) yang berhasil melakukan optimasi dengan pendekatan full factorial design dalam proses drilling, di mana terdapat faktor interaksi di dalamnya karena faktor tersebut ternyata memiliki pengaruh yang signifikan.

\section{Metode}

Tujuan utama pada penelitian ini adalah mengetahui perbedaan pengaruh dari variebel-variebel yang berpengaruh pada inspeksi pengukuran luas dan defect pada permukaan ubin keramik sehingga dapat menghasilkan faktor yang berpengaruh 
terhadap tingkat akurasi pengukuran. Penelitian ini menggunakan dua faktor, yaitu intensitas cahaya dan jarak pengambilan citra sesuaidengan prosedur SNI ISO 105452:2010. Untuk level masing-masing faktor ditentukan berdasarkan prosedur yang terdapat pada SNI ISO 10545-2:2010 dan penelitian pendahuluan. Intensitas cahaya yang digunakan untuk inspeksi visual berdasarkan SNI ISO 10545-2:2010 sebesar 300 lx pada permukaan ubin. Standar tersebut digunakan sebagai low level. Untuk medium level digunakan intensitas cahaya sebesar 600 lx dan high level sebesar 900 lx. Untuk jarak pengambilan gambar didasarkan pada acuan yang tertera pada SNI ISO 105452:2010 yaitu $100 \mathrm{~cm}$, tetapi jarak tersebut dapat disesuaikan sesuai dengan kebutuhan inspeksi. Berdasarkan hasil pengamatan dilapangan user yang bertugas melakukan inspeksi pada jarak $50 \mathrm{~cm}$ hal ini dilakukan untuk melihat kualitas permukaan keramik lebih detail. Untuk low level jarak pengambilan citra digunakan jarak $50 \mathrm{~cm}$, medium level 75 $\mathrm{cm}$, dan high level sebesar $100 \mathrm{~cm}$.

Berdasarkan hasil studi pendahuluan yang dilakukan akan diketahui parameterparameter yang mempengaruhi proses identifikasi citra ubin keramik dan dipilih 2 parameter yang dianggap paling berpengaruh terhadap hasil identifikasi citra ubin keramik. Parameter yang dipilih adalah luas ubin dan diameter defect jenis dry spots pada permukaan ubin.Pada Tabel 1 ditunjukkan hasil konversi luas ubin sebenarnya ke dalam piksel dan didapatkan luas ubin yang berbeda-beda berdasarkan jarak pengambilan citra. Pada Tabel 2 diperoleh hasil konversi diameter dry spots sebenarnya ke dalam bentuk pixel.

Tabel 1

Data Acuan Luas Ubin Normal Keramik

\begin{tabular}{l|l|l|l}
\hline No & Jarak (cm) & Sisi (pixel) & \multicolumn{1}{|c}{ Luas Ubin (pixel) } \\
\hline 1 & 50 & 411 & 168921 \\
\hline 2 & 75 & 269 & 72361 \\
\hline 3 & 100 & 208 & 43264 \\
\hline
\end{tabular}

Tabel 2

Data Acuan Diameter Dry Spots Max Ubin Defect

\begin{tabular}{l|l|l|l}
\hline No & Jarak (cm) & \multicolumn{1}{|c|}{$\begin{array}{c}\text { Diameter Max } \\
(\mathbf{c m})\end{array}$} & $\begin{array}{c}\text { Diameter Max } \\
\text { (pixel) }\end{array}$ \\
\hline 1 & 50 & 5.23 & 7.17 \\
\hline 2 & 75 & 5.23 & 4.69 \\
\hline 3 & 100 & 5.23 & 3.63 \\
\hline
\end{tabular}

Tahapan selanjutnya adalah menyusun desain ekperimen yang meliputi faktor, level, dan jumlah replikasinya. Jumlah faktor yang digunakan tergantung dari parameter yang dipilih, sedangkan level yang akan digunakan terdiri dari 3 level yaitu low, medium, dan high.Untuk memudahkan dalam mengetahui tingkat akurasi khususnya tingkat error dari proses pengukuran, maka diperlukan sebuah media antar muka (interface) yang terdapat pada menu library Matlab, yaitu dengan menggunakan GUI (Graphical User Interface).Penelitian ini juga menggunakan kerangka rig dalam proses pengambilan citra. Kerangka peraga terbuat dari besi dengan ukuran $120 \times 50 \times 100 \mathrm{~cm}$. Kerangka peraga digunkan untuk tempat webcam yang dugunakan untuk proses pengambilan gambar dan mengatur jarak webcam serta sebagai tempat untuk meletakkan sumber cahaya dari lampu LED 10 watt. Kerangka rig penelitian tersebut dapat ditunjukkan pada Gambar 1.

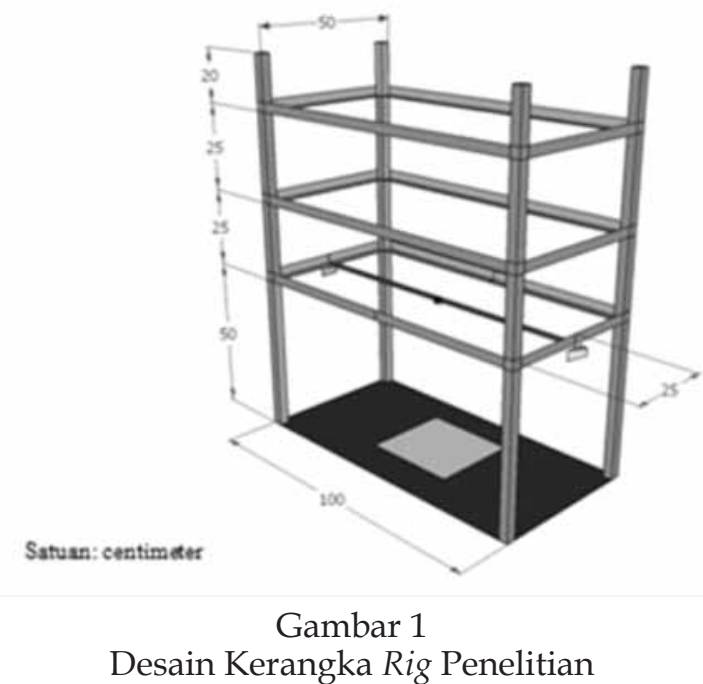

Desain Kerangka Rig Penelitian 
Untuk mendapatkan intensitas cahaya sesuai dengan level yang ditentukan, pada penelitian ini digunakan sumber cahaya dari lampu LED 10 watt dengan melakukan pengaturansebagaiberikut:pertama,Intensitas cahaya 300 lx diperoleh dari dua buah lampu yang dipasang di sisi kanan dan kiri kerangka rig penelitian dengan posisi di tengah-tengah atau $25 \mathrm{~cm}$ dari kerangka yang dapat dilihat pada Gambar 2 (a). Pengaturan arah cahaya dilakukan secara manual dengan mengatur posisi cahaya dari lampu. Cahaya diarahkan ke ubin keramik dan diukur dengan lux metter untuk menghitung intensitas cahaya. Ketika intensitas cahaya sudah tepat pada intensitas cahaya 300lx selanjutnya arah dan posisi lampu dikunci dengan menggunakan screw agar posisi tidak berubah-ubah.

Kedua,Intensitas cahaya 600 lx diperoleh dari empat buah lampu yang dipasang di sisi kanan dua buah lampu, dan sisi kiri dua buah lampu. Sama seperti yang dilakukan pada setup cahaya 300lx, tetapi masingmasing sisi terdapat dua buah lampu yang dipasang di tengah-tengah atau $25 \mathrm{~cm}$ dari kerangka yang dapat dilihat pada Gambar 2 (b). Pengaturan arah cahaya dilakukan secara manual dengan mengatur posisi cahaya dari lampu. Cahaya diarahkan ke ubin keramik dan diukur dengan lux metter untuk menghitung intensitas cahaya. Ketika intensitas cahaya sudah tepat pada intensitas cahaya 600lx, selanjutnya arah dan posisi lampu di kunci dengan menggunakan screw agar posisi tidak berubah-ubah.

Ketiga,Intensitas cahaya 900lx diperoleh dari empat buah lampu yang dipasang di sisi kanan satu buah lampu, sisi kiri satu buah lampu sisi depan dan sisi belakang satu buah lampu. Sama seperti yang dilakukan pada setup cahaya sebelumnya namun pada sisi kanan dan dikiri lampu dipasang di tengahtengah atau $25 \mathrm{~cm}$ sedangkan pada sisi depan dan belakang dipasang pada jarak $50 \mathrm{~cm}$ kerangka atau dapat dilihat pada Gambar 2 (c). Pengaturan arah cahaya dilakukan secara manual dengan mengatur posisi cahaya dari lampu. Cahaya diarahkan ke ubin keramik dan diukur dengan lux metter untuk menghitung intensitas cahaya. Ketika intensitas cahaya sudah tepat pada intensitas cahaya 900lx, selanjutnya arah dan posisi lampu di kunci dengan menggunakan screw agar posisi tidak berubah-ubah.

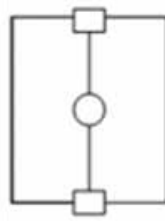

(a)

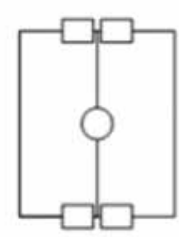

(b)

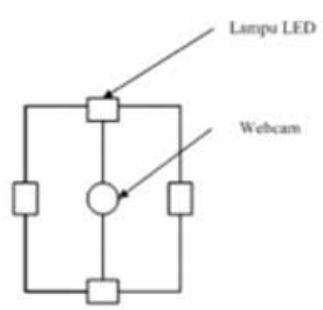

(c)
Gambar 2

Tata Letak Lampu LED (a) 300lx, (b) 6001x, dan (c) $9001 \mathrm{x}$

Pada aplikasi pengukuran luas ubin keramik, variabel input yang dibutuhkan adalah citra ubin keramik yang meliputi nama citra, ukuran citra, dan dimensi dari citra tersebut yang disesuaikan dengan jarak pengambilan citra kemudian variabel outputnya adalah luas ubin, penyimpangan pengukuran dan waktu komputasi. Pada aplikasi ini juga ditambahkan komponen lain untuk menampilkan proses pengolahan citra yang diukur meliputi proses identifikasi dan pre-processing dengan menambahkan 2 axes.

Pada aplikasi pengukuran diameter dry spots ubin keramik, variabel input yang dibutuhkan adalah citra ubin keramik yang meliputi nama citra, ukuran citra, dan dimensi dari citra tersebut yang disesuaikan dengan jarak pengambilan citra dan pengaturan tingkat kecerahan (brightness) kemudian variabel outputnya adalah luas keseluruhan dry spots, diameter dry spots maksimum, penyimpangan pengukuran dan waktu komputasi. Pada aplikasi ini juga ditambahkan komponen lain untuk menampilkan proses pengolahan citra yang diukur meliputi proses identifikasi dan pre- 
processing dan hasil identifikasi dry spots ubin keramik dengan menambahkan 3 axes.

Langkah selanjutnya adalah melakukan perancangan algoritma yang digunakan untuk identifikasi luas permukaan keramik dan identifikasi dry spots (defect). Tahapantahapan yang digunakan untuk menghitung luas permukaan ubin keramik berdasarkan area citra adalah sebagai berikut: pertama,Mengubah citra dari RGB menjadi grayscale

Tahapan awal yang dilakukan untuk memudahkan dalam proses identifikasi ubin adalah dengan mengkonversi citra RGB dalam bentuk grayscale. Tujuan konversi ini agar lebih memudahkan dalam melakukan analisis citra yang diperlukan pada proses tahapan pengolahan citra selanjutnya. Kedua, Mengubah citra grayscale menjadi citra biner Citra jenis ini banyak dipakai dalam pemrosesan citra, misalnya untuk kepentingan memperoleh tepi bentuk suatu objek (Kadir dan Susanto 2013).

Ketiga, Deteksi Tepi Metode deteksi yang digunakan pada penelitian ini adalah operator canny. Algoritma ini memberikan tingkat kesalahan yang sangat rendah, melokalisasi titik-titik tepi (jarak piksel-piksel tepi yang ditemukan deteksi dan tepi yang sesungguhnya sangat pendek), dan hanya memberikan satu tanggapan untuk satu tepi. Keempat, Operasi Filling digunakan untuk proses rekrontruksi dengan cara mengubah pixel-pixel pada latar belakangyang terhubung (0) menjadi pixel yang tampak (1) sehingga didapatkan hasil secara jelas dengan operasi flood fill. Kelima, Perhitungan luas ubin. Operasi morfologi untuk menghitung area citra yang digunakan untuk menghitung luas permukaan ubin dengan cara menghitung keseluruhan pixel yang berwarna putih atau bernilai 1 dengan perintah bwarea. Keenam, Perhitungan simpangan pengukuran. Nilai hasil perhitungan luas ubin akan dibandingkan dengan luas acuan keramik untuk mendapatkan selisih dari hasil pengukuran untuk kemudian dijadikan sebagai nilai error hasil pengukuran dengan menggunakan operasi pengurangan absolute.

Tahapan selanjutnya adalah perancangan algoritma untuk indentifikasi jenis defect dry spots adalah sebagai berikut:

a. Mengubah citra dari RGB menjadi grayscale;

b. Operasi imcrop;

Operasi imcrop digunakan untuk melakukan pemotongan pada citra. Tujuan pemotongan ini adalah untuk mendapatkan secara spesifik bentuk objek serta defect yang terdapat pada permukaan keramik khususnya dry spots.

c. Pengaturan nilai kontras;

Agar dry spots dapat terdeteksi khususnya dengan deteksi tepi, maka tingkat kecerahan (brightness) pada citra perlu di geser ke arah kiri atau tingkat kecerahannya dikurangi, khususnya pada tingkat kecerahan 600lx dan 900lx hal ini didasarkan pada hasil percobaan yang telah dilakukan sebelumnya seperti pada Gambar 1.

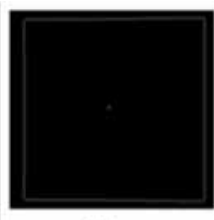

(a)

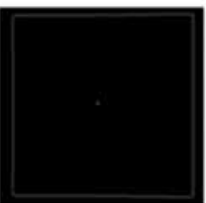

(b)

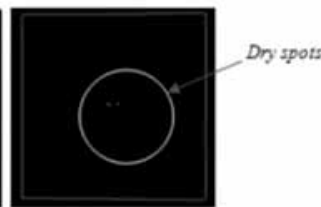

(c)
Gambar 3

Pengaturan Nilai Kecerahan pada Intensitas Cahaya 600lx, (a) Tanpa Penurunan, (b) 45, dan (c) 90

d. Deteksi tepi (canny);

e. Operasi filling;

f. Algoritma pencarian panjang dan lebar dry spots;

Algoritma yang digunakan untuk mendapatkan nilai panjang dan lebar dry spots, sebagai berikut:

Panjang=sum(BWdim);

$x 2=\max ($ find $($ panjang $>0))$;

$x 1=\min ($ find $($ panjang $>0))$; 
lebar=sum(BWdim,2);

y2 $=\max ($ find $($ lebar $>0))$;

$\mathrm{y} 1=\min ($ find $($ lebar $>0))$;

width=x2-x1;

height=y2-y1;

g. Algoritma pencarian diameter max dry spots;

Untuk menghitung diameter maksimum dry spots, maka hasil pencarian panjang dan lebar diubah dulu dalam bentuk binary dan dicari jumlah nilai pixel maximumnya.

$\mathrm{A}=\mathrm{im} 2 \mathrm{bw}$ (panjang);

$\mathrm{B}=\operatorname{im} 2 \mathrm{bw}(\mathrm{lebar})$;

$\mathrm{AA}=\operatorname{sum}(\mathrm{A})$;

$\mathrm{BB}=\operatorname{sum}(\mathrm{B})$;

Diameter_dryspot $=\max (\mathrm{AA}, \mathrm{BB})$

Tahapan selanjutnya adalah melakukan pengumpulan datauntuk dapat mengamati lebih dalam, maka pendekatan yang digunakan dalam penelitian ini adalah full factorial design dan dilakukan sebanyak tiga kali replikasi untuk memastikan kepresisian hasil. Selanjutnya akan dicari nilai rataratanya sebagai respon dari masing-masing kombinasi.

Setelah didapatkan data yang dibutuhkan, maka langkah selanjutnya adalah dilakukan analisis statistik dengan melaku- kan uji normalitas data.Jika distribusi yang didapat normal, maka dilakukan uji parametrik dengan menggunakan ANOVA, tetapi jika tidak maka dilakukan uji non parametric dengan menarik keputusan terkait ada tidaknya pengaruh dari faktor terhadap penelitian. Selanjutnya jika faktor interaksi berpengaruh secara signifikan maka lakukan uji post hoc.

Tahapan terakhir dari penelitian ini adalah hasil yang telah didapat akan dirangkum serta diambil kesimpulan dan diberikan saran tentang arahan pengembangan penelitian selanjutnya.

\section{HASIL DAN PEMBAHASAN \\ Analisis Image Processing}

Pada tahapan image processing ini akan menampilkan variabel yang berpengaruh terhadap inspeksi kualitas permukaan ubin dengan teknik pengolahan citra. Data yang digunakan adalah citra hasil eksperimen pada intensitas cahaya 300lx dengan jarak pengambilan gambar $50 \mathrm{~cm}$.

\section{Pengaruh Kualitas Citra}

Untuk mengetahui pengaruh ukuran citra (pixel/image) terhadap luas ubin keramik yang dihasilkan, maka dilakukan beberapa perubahan (resize) terhadap ukuran piksel citra.Tabel 5.1 merupakan hasil dari pengujian kompresi citra dengan variasi kompresi yang berbeda-beda.

Tabel 3

Nilai Tingkat Error Pengukuran Luas Ubin Normal (resize)

\begin{tabular}{l|l|l|l|l|l|l|l}
\hline \multicolumn{1}{c|}{ Image } & Resize (\%) & Dimension & $\begin{array}{c}\text { Size } \\
\text { (bytes) }\end{array}$ & $\begin{array}{c}\text { Luas Pengukuran } \\
(\mathbf{p i x e l )}\end{array}$ & $\begin{array}{c}\text { Luas Ubin } \\
(\mathbf{c m})\end{array}$ & $\begin{array}{c}\text { Tingkat Error } \\
(\mathbf{\%})\end{array}$ & $\begin{array}{c}\text { Time } \\
(\mathbf{s})\end{array}$ \\
\hline resize150 & 150 & $900 \times 1200$ & 35300 & 379151,0 & 1346,73 & 0,242 & 0,97 \\
\hline resize140 & 140 & $840 \times 1120$ & 30268 & 330430,0 & 1257,51 & 0,198 & 0,85 \\
\hline resize130 & 130 & $780 \times 1040$ & 26931 & 285091,0 & 1168,42 & 0,135 & 0,68 \\
\hline resize120 & 120 & $720 \times 960$ & 23253 & 243021,0 & 1079,00 & 0,093 & 0,59 \\
\hline resize110 & 110 & $660 \times 881$ & 20645 & 204307,0 & 989,58 & 0,043 & 0,56 \\
\hline Original & 100 & $600 \times 800$ & 52139 & 169069,0 & 900,79 & 0,088 & 0,50 \\
\hline resize90 & 90 & $540 \times 720$ & 14386 & 136931,0 & 810,62 & 0,077 & 0,35 \\
\hline resize80 & 80 & $480 \times 640$ & 11831 & 108306,0 & 721,31 & 0,182 & 0,30 \\
\hline
\end{tabular}




\begin{tabular}{l|l|l|l|l|l|l|l}
\hline \multicolumn{1}{c|}{ Image } & Resize (\%) & Dimension & $\begin{array}{c}\text { Size } \\
(\text { bytes) }\end{array}$ & $\begin{array}{c}\text { Luas Pengukuran } \\
(\mathbf{p i x e l )}\end{array}$ & $\begin{array}{c}\text { Luas Ubin } \\
(\mathbf{c m})\end{array}$ & $\begin{array}{c}\text { Tingkat Error } \\
(\mathbf{\%})\end{array}$ & $\begin{array}{c}\text { Time } \\
(\mathbf{s})\end{array}$ \\
\hline resize60 & 60 & $360 \times 480$ & 7343 & 61072,6 & 542,32 & 0,429 & 0,20 \\
\hline resize50 & 50 & $300 \times 400$ & 5528 & 42489,8 & 452,77 & 0,615 & 0,16 \\
\hline resize40 & 40 & $240 \times 320$ & 4004 & 27273,9 & 363,28 & 0,912 & 0,12 \\
\hline resize30 & 30 & $180 \times 240$ & 2831 & 15427,9 & 274,00 & 1,480 & 0,08 \\
\hline resize20 & 20 & $120 \times 160$ & 1846 & 6917,4 & 184,28 & 2,376 & 0,09 \\
\hline resize10 & 10 & $60 \times 80$ & 1118 & 1766,3 & 94,10 & 4,561 & 0,07 \\
\hline
\end{tabular}

Pada pengujian terhadap citra original ukuran $600 \times 800$ menghasilkan tingkat error sebesar 0,088\% dengan waktu komputasi 0,50 s, untuk kompresi citra $90 \%$ atau540 x 720 piksel menghasilkan tingkat error pengukuran sebesar $0,077 \%$ dengan waktu komputasi 0,35 s sedangkan pada kompresi citra $80 \%$ sampai $10 \%$ tingkat error pengukuran ubin cenderung lebih besar. Untuk kompresi citra sebesar 110\% dengan ukuran citra $660 \times 881$ piksel menghasilkan tingkat error sebesar 0,043\%lebih kecil dari ukuran citra aslinya, namun dengan perbesaran $120 \%$ sampai $150 \%$ menghasilkan tingkat error yang semakin besar. Pada Tabel 3 waktu komputasi perhitungan luas ubin berkurang seiring dengan pengurangan ukuran citra, begitu juga waktu komputasi akan bertambah sering dengan perbesaran terhadap ukuran citra.

\section{Evaluasi Aras Keabuan (Grayscale)}

Pada percobaan selanjutnya akan dilakukan kombinasi perubahan bobot variabel RGB berdasarkan standar dari NTSC. Untuk mengetahui pengaruh dari hasil konversi skala keabuan, maka akan dilakukan uji coba terhadap kombinasi dari bobot nilai RGB seperti pada Tabel 4. Asumsi yang digunakan pada percobaan ini adalah perubahan hanya dilakukan pada hasil konversi grayscale.

Tabel 4

Perubahan Nilai Variabel Komponen RGB Terhadap Luas Ubin Keramik

\begin{tabular}{|c|c|c|c|c|c|c|c|c|}
\hline \multirow[t]{2}{*}{ Image } & \multicolumn{3}{|c|}{$\begin{array}{c}\text { Komposisi Variabel Komponen } \\
\text { RGB }\end{array}$} & \multirow[t]{2}{*}{ Size (bytes) } & \multicolumn{2}{|c|}{ Luas } & \multirow{2}{*}{$\begin{array}{c}\text { Tingkat Error } \\
(\%)\end{array}$} & \multirow[t]{2}{*}{ Time (s) } \\
\hline & $\mathbf{R}$ & $G$ & B & & Pixel & $\mathrm{Cm}^{2}$ & & \\
\hline gray1 & 0,2989 & 0,5870 & 0,1140 & 15787 & 169076 & 900,83 & 0,092 & 0,49 \\
\hline gray2 & 0,2989 & 0,1140 & 0,5870 & 16925 & 169051 & 900,69 & 0,077 & 0,54 \\
\hline gray3 & 0,5870 & 0,2989 & 0,1140 & 15822 & 169077 & 900,83 & 0,092 & 0,48 \\
\hline gray4 & 0,5870 & 0,1140 & 0,2989 & 16236 & 169084 & 900,87 & 0,096 & 0,44 \\
\hline gray5 & 0,1140 & 0,2989 & 0,5870 & 16446 & 169059 & 900,74 & 0,082 & 0,49 \\
\hline gray6 & 0,1140 & 0,5870 & 0,2989 & 16022 & 169060 & 900,74 & 0,082 & 0,45 \\
\hline gray7 & 0,3333 & 0,3333 & 0,3333 & 15984 & 169081 & 900,85 & 0,095 & 0,45 \\
\hline rgb2gray & \multicolumn{3}{|l|}{ default } & 15204 & 169078 & 900,84 & 0,093 & 0,45 \\
\hline Original & \multicolumn{3}{|l|}{ default } & 52139 & 169069 & 900,79 & 0,088 & 0,50 \\
\hline
\end{tabular}

Untuk citra gray hasil dari konversi dari RGB menjadi citra beraras kebaun memiliki tingkat error 0,077\% dengan komposisi variabel bobot $R=0,2989, G=0,1140$, dan $\mathrm{B}=0,5870$. Sehingga untuk program untuk mengkonversi RGB menjadi grayscale pada Matlab digunakan perintah di bawah ini:

$$
>>\text { gray } 2=(0.2989 * \text { red })+(0.1140 * \text { green })+(0.5
$$
$870 *$ blue)

\section{Citra Biner}

Pada Tabel 5 menunjukkan dengan citra inputan yang sama, tetapi metode kompresi citra menjadi grayscale serta penentuan nilai threshold memberikan pengaruh terhadap tingkat error yang dihasilkan dan processing time. Pada percobaan ini didapatkan metode kompresi citra menjadi grayscale digunakan ektraksi RGB dan untuk menentukan nilai 
threshold menggunakan nilai default dari sistem sebesar 0,5. Sehingga dihasilkan tingkat error yang lebih kecil sebesar 0,075\%.

\section{Pengaruh Kecerahan dan Kontras}

Selanjutnya akan dilakukan pengujian pengaruh tingkat kecerahan dan kontras terhadap tingkat error pengukuran luas permukaan ubin. Pada Tabel 5.4 menunjukkan beberapa kombinasi antara tingkat kecerahan serta kontras pada citra ubin. Hasilnya dapat dilihat bahwa citra ubin dengan pengurangan tingkat kecerahan 5 menghasilkan tingkat error yang lebih kecil disbanding dengan citra ubin aslinya maupun citra ubin yang ditambah tingkat kecerahan, kontrasnya, maupun kombinasi dari tingkat kecerahan dan kontras.

Tabel 5

Pengaruh Nilai Threshold pada Citra Biner

\begin{tabular}{|c|c|c|c|c|c|c|c|c|}
\hline \multirow{2}{*}{ Image } & \multirow{2}{*}{$\begin{array}{c}\text { Size } \\
\text { (bytes) }\end{array}$} & \multirow{2}{*}{ Metode } & \multirow{2}{*}{$\begin{array}{c}\text { Nilai } \\
\text { Threshold }\end{array}$} & \multicolumn{2}{|c|}{ Luas } & \multirow{2}{*}{$\begin{array}{l}\text { Tingkat } \\
\text { Error }(\%)\end{array}$} & \multirow{2}{*}{$\begin{array}{c}\text { Time } \\
(\mathrm{s})\end{array}$} & \multirow{2}{*}{$\begin{array}{c}\text { Keterangan } \\
\text { (Metode Grayscale) }\end{array}$} \\
\hline & & & & Pixel & $\mathrm{Cm} 2$ & & & \\
\hline Original & 52139 & Default & 0,500 & 169069 & 900,79 & 0,088 & 0,53 & rgb2gray \\
\hline Original & 52139 & Otsu & 0,475 & 169142 & 901,18 & 0,131 & 0,48 & rgb2gray \\
\hline Original & 52139 & Otsu & 0,467 & 169151 & 901,23 & 0,136 & 0,77 & Ektraksi RGB \\
\hline Original & 52139 & Default & 0,500 & 169047 & 900,67 & 0,075 & 0,44 & Ektraksi RGB \\
\hline
\end{tabular}

Perancangan Tampilan Antar Muka

Untuk memudahkan dalam mengetahui tingkat akurasi, khususnya tingkat error dari proses pengukuran, maka diperlukan sebuah media antar muka (interface) yang terdapat pada menu library Matlab. Bentuk rancangan tampilan antarmuka bagi pengguna dapat digambarkan secara sederhana pada Gambar 5.

Tabel 6

Pengaruh Kecerahan dan Kontras

\begin{tabular}{|c|c|c|c|c|c|c|c|c|c|}
\hline \multirow[t]{2}{*}{ Image } & \multirow{2}{*}{$\begin{array}{c}\text { Size } \\
\text { (bytes) }\end{array}$} & \multicolumn{2}{|c|}{ Kecerahan } & \multirow[t]{2}{*}{ Kontras } & \multicolumn{2}{|c|}{ Luas } & \multirow{2}{*}{$\begin{array}{c}\text { Tingkat Error } \\
(\%)\end{array}$} & \multirow{2}{*}{$\begin{array}{c}\text { Time } \\
\text { (s) }\end{array}$} & \multirow[t]{2}{*}{ Ket. } \\
\hline & & + & - & & Pixel & $\mathrm{Cm}^{2}$ & & & \\
\hline Original & 52139 & - & - & - & 169069 & 900,79 & 0,088 & 0,53 & \\
\hline \multirow[t]{2}{*}{ Original } & \multirow[t]{2}{*}{52139} & - & 5 & - & 168873 & 899,74 & 0,028 & 0,42 & \\
\hline & & 5 & - & - & 169120 & 901,06 & 0,118 & 0,60 & \\
\hline Original & 52139 & - & - & 2,5 & 1665,63 & 8,87 & 99,014 & 0,77 & Gagal deteksi \\
\hline \multirow[t]{2}{*}{ Original } & \multirow[t]{2}{*}{52139} & - & 5 & 2,5 & 170016 & 905,83 & 0,648 & 0,45 & \\
\hline & & 5 & - & & 1849,5 & 9,85 & 98,905 & 0,43 & Gagal deteksi \\
\hline
\end{tabular}
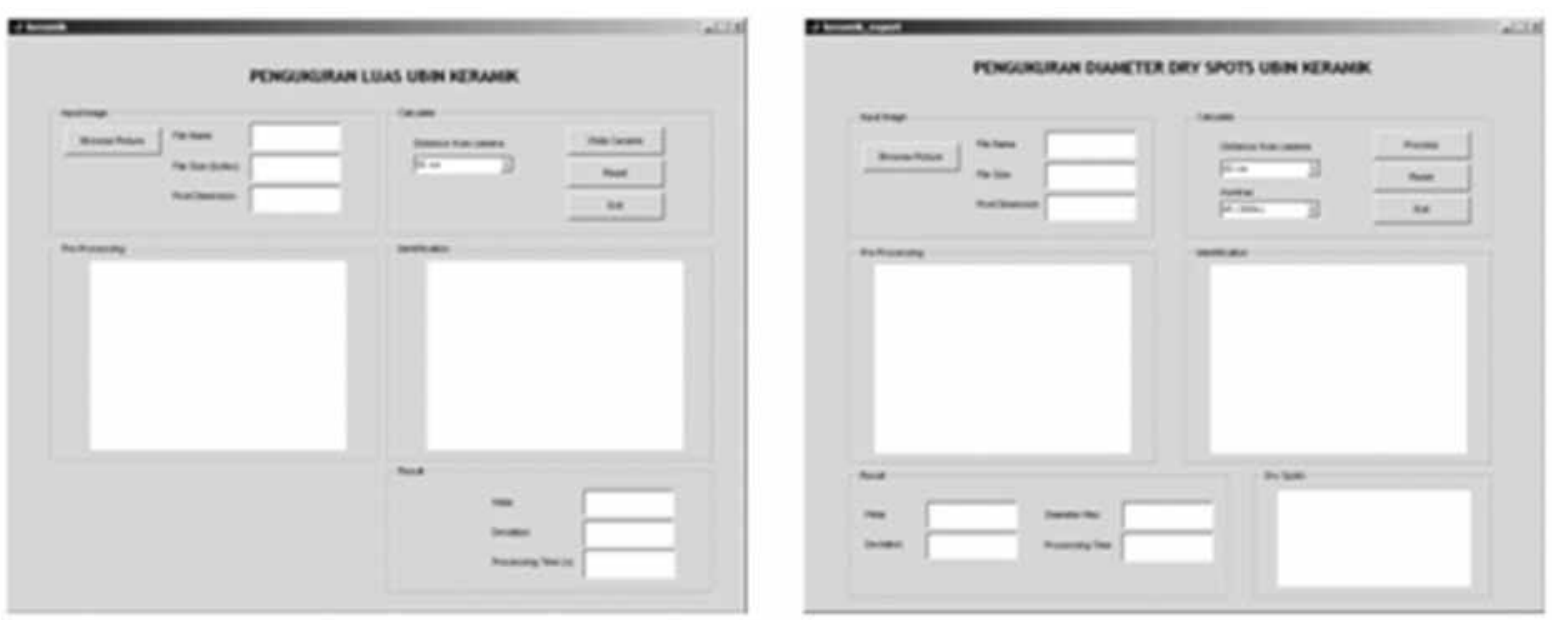

Gambar 4

Tampilan GUI Program 


\section{Desain Eksperimen}

Setelah dilakukan beberapa kali studi pendahuluan, maka langkah selanjutnya adalah melakukan desain ekperimen dengan menggunakan dua faktor dan tiga level dengan rincian pada Tabel 7. Tujuan dilakukan ekperimen ini adalah untuk mendapatkan nilai respon tingkat error yang minimal dengan melakukan perubahan intensitas cahaya dan jarak kamera. pada penelitian ini akan digunakan 27 jenis perlakuan. Berdasarkan persamaan Feeder (1995), maka didapatkan jumlah replikasi yang dilakukan minimal adalah 3 .

Tabel 7

Kode Faktor dan Level

\begin{tabular}{l|l|l|c}
\hline \multirow{2}{*}{ Faktor } & \multicolumn{3}{|c}{ Level } \\
\cline { 2 - 4 } & \multicolumn{1}{c|}{$\mathbf{1}$} & \multicolumn{1}{c}{$\mathbf{0}$} & $\mathbf{1}$ \\
\hline I Intensitas Cahaya (lx) & 300 & 600 & 900 \\
\hline S Jarak Kamera (cm) & 50 & 75 & 100 \\
\hline
\end{tabular}

Setelah menentukan RAL maka langkah selanjutnya adalah melakukan proses pengambilan citra berdasarkan run order, kemudian dilakukan analisis lebih lanjut untuk mengetahui tingkat error pengukuran luas dan defect pada ubin keramik. Gambar 5 menunjukkan persentase tingkat error pengukuran luas ubin tertinggi diperoleh pada intensitas cahaya 900 lx dengan jarak kamera $75 \mathrm{~cm}$ sebesar 1,0627\%, sedangkan persentase tingkat error pengukuran luas ubin terendah diperoleh pada intensitas cahaya $300 \mathrm{~lx}$ dengan jarak $50 \mathrm{~cm}$ sebesar 0,0675\%.

Pada Gambar 5 juga terlihat bahwa intensitas cahaya $600 \mathrm{~lx}$ dan $900 \mathrm{~lx}$ pada jarak kamera $50 \mathrm{~cm}, 75 \mathrm{~cm}$, dan $100 \mathrm{~cm}$ menghasilkan nilai error perhitungan luas ubin yang semakin besar dari luas ubin sebenarnya, sehingga mengakibatkan nilai penyimpangan luas ubin lebih besar dari luas ubin secara perhitungan manual.

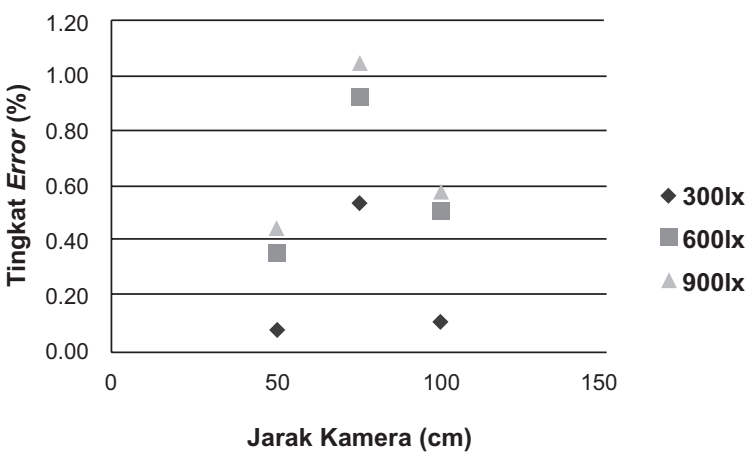

Gambar 5

Grafik Pebandingan Tingkat Error Pengukuran Luas Ubin

Gambar 6 menunjukkan persentase tingkat error, pengukuran defect permukaan ubin jenis dry spots tertinggi diperoleh pada intensitas cahaya 300 lx dan 600 lx dengan kamera $75 \mathrm{~cm}$ sebesar 37,89\%, sedangkan persentase tingkat error pengukuran luas ubin terkecil diperoleh pada intensitas cahaya 300 lx dengan jarak $50 \mathrm{~cm}$ sebesar 2,30\%.

Pada Gambar 6 juga terlihat bahwa semakin tinggi intensitas cahaya dan jarak kamera maka akan menyebabkan tingkat error dari hasil pengukuran akan semakin besar, sehingga nilai penyimpangan diameter dry spots yang dilakukan pengukuran akan semakin besar dari nilai acuannya.

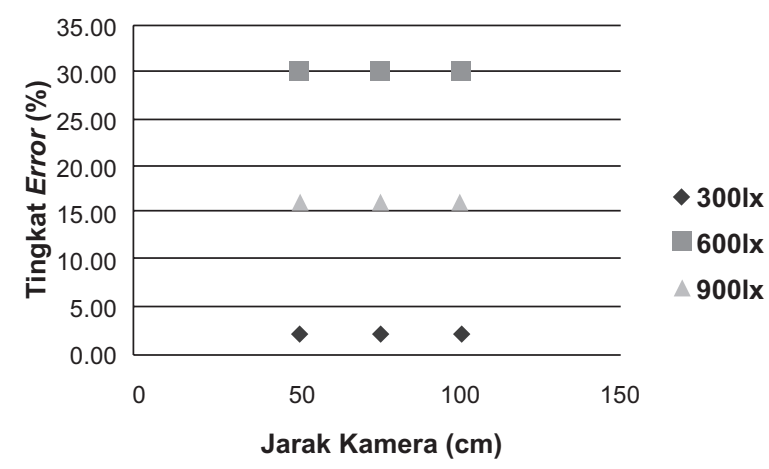

Gambar 6

Grafik Pebandingan Tingkat Error Pengukuran Dry Spots (Defect) 


\section{Analisis Statistik}

Setelah data terkumpul dan dilakukan pengolahan data, maka langkah selanjutnya adalah melakukan analisis statistik dari data yang diperoleh untuk mengetahui distribusi sebaran data, faktor atau variabel independen yang memiliki pengaruh yang signifikan terhadap variabel dependen.

\section{Uji Normalitas}

Untuk memberikan kepastian, data yang dimiliki berdistribusi normal atau tidak, sebaiknya digunakan uji statistik normalitas. Belum tentu data yang lebih dari 30 bisa dipastikan berdistribusi normal, demikian sebaliknya data yang banyaknya kurang dari 30 belum tentu tidak berdistribusi normal, untuk itu perlu suatu pembuktian. Tabel 7 merupakan uji normal dengan menggunakan SPSS V.20.

Tabel 7

Uji Normalitas Respon

\begin{tabular}{l|l|l}
\hline \multirow{1}{*}{ Data } & \multicolumn{2}{c}{ Kolmogorov-Smirnov } \\
\cline { 2 - 3 } & \multicolumn{1}{c}{ Sig. } & \multicolumn{1}{c}{ Hasil } \\
\hline $\begin{array}{l}\text { Tingkat error pengukuran } \\
\text { luas ubin }\end{array}$ & 0.221 & Normal \\
\hline $\begin{array}{l}\text { Tingkat error pengukuran } \\
\text { diameter dry spots }\end{array}$ & 0.179 & Normal \\
\hline
\end{tabular}

Berdasarkan Tabel 7 hasil uji normalitas didapat nilai $P$-value $>$ a $(5 \%)$ maka dapat disimpulkan sebaran data terdistribusi normal sehingga inferensi statistik (pengambilan keputusan) dapat dilakukan dengan pengujian parametrik.

\section{Analysis of Variance untuk Respon Tingkat Error}

Beberapa hal yang dihitung dalam ANOVA seperti degree of freedom (df), sum of square (SS), dan mean square (MS) serta F hitung.

$$
\begin{aligned}
& \mathrm{df}=\mathrm{n}_{\text {level }}-1 \\
& \mathrm{SS}_{\mathrm{T}}=\sum_{\mathrm{i}=1}^{\mathrm{a}} \sum_{\mathrm{j}=1}^{\mathrm{b}} \sum_{\mathrm{k}=1}^{\mathrm{n}} \mathrm{y}^{2}{ }_{\mathrm{ijk}}-\frac{\mathrm{y}^{2} \ldots}{\mathrm{abn}} \\
& \mathrm{SS}_{\mathrm{A}}=\frac{1}{\mathrm{bn}} \sum_{\mathrm{i}=1}^{\mathrm{a}} \mathrm{y}^{2}{ }_{\mathrm{i} . .}-\frac{\mathrm{y}^{2} \ldots}{\mathrm{abn}}
\end{aligned}
$$

$$
\begin{aligned}
& \mathrm{SS}_{\mathrm{B}}=\frac{1}{\mathrm{an}} \sum_{\mathrm{j}=1}^{\mathrm{b}} \mathrm{y}^{2}{ }_{\mathrm{j} .}-\frac{\mathrm{y}^{2} \ldots}{\mathrm{abn}} \\
& \mathrm{SS}_{\mathrm{AB}}=\frac{1}{\mathrm{n}} \sum_{\mathrm{i}=1}^{\mathrm{a}} \sum_{\mathrm{j}=1}^{\mathrm{b}} \mathrm{y}^{2}{ }_{\mathrm{ij} .}-\frac{\mathrm{y}^{2} \ldots}{\mathrm{abn}}-\mathrm{SS}_{\mathrm{A}}-\mathrm{SS}_{\mathrm{B}} \\
& \mathrm{SS}_{\mathrm{E}}=\mathrm{SS}_{\mathrm{T}}-\mathrm{SS}_{\mathrm{A}}-\mathrm{SS}_{\mathrm{B}}-\mathrm{SS}_{\mathrm{AB}} \\
& \mathrm{MS}=\frac{\mathrm{SS}}{\mathrm{df}}
\end{aligned}
$$

$$
\text { Fhitung }=\frac{\mathrm{MS}}{\mathrm{MS}_{\mathrm{E}}}
$$

Dengan:

$\mathrm{df}=$ degree of freedom

$\mathrm{SS}_{\mathrm{T}} \quad=$ Sum of Square Total

$\mathrm{SS}_{\mathrm{A}}=$ Sum of Square Faktor $\mathrm{A}$

$\mathrm{SS}_{\mathrm{B}}=$ Sum of Square Faktor B

$\mathrm{SS}_{\mathrm{AB}}=$ Sum of Square Interaksi

Faktor AB

$\mathrm{SS}_{\mathrm{E}} \quad=$ Sum of SquareError

MS = Mean Square

$\mathrm{F}_{\text {hitung }}=$ Nilai $\mathrm{F}$ hasil perhitungan

Berdasarkan Tabel 8 nilai Ftabel ( $a$, df1, df2) yaitu $F$ tabel $(0,05,2,18)$ untuk faktor intensitas cahaya dan jarak kamera sebesar 3,55, sedangkan hasil pengolahan data diketahui bahwa nilai $\mathrm{F}$ hitung sebesar 5828,65 untuk intensitas cahaya dan 3923,87 untuk jarak kamera. Selain itu F tabel $(0,05$, 4,18 ) untuk interaksi sebesar 2,93 dan nilai $\mathrm{F}$ hitung sebesar 46,13 . Ini berarti nilai $\mathrm{F}$ hitung untuk semua faktor dan interaksi tersebut $>\mathrm{F}$ tabel atau nilai $\mathrm{P}$-value $<(\alpha=5 \%)$, maka keputusan yang dapat diambil adalah menolak $\mathrm{H}_{0}$ ini berarti variabel intensitas cahaya dan jarak kamera maupun interaksi, secara keseluruhan mempunyai pengaruh yang signifikan terhadap respon tingkat error dari hasil pengukuran luas ubin. Semakin besar nilai $\mathrm{F}$ hitung menunjukkan semakin besar pula pengaruhnya, sehingga urutan pengaruhnya dari besar ke kecil adalah jarak kamera, intensitas cahaya, dan interaksi kedua faktor. 
Tabel 8

Analysis of Variance untuk Respon Tingkat Error Pengukuran Luas Ubin

\begin{tabular}{l|l|l|l|l|ll}
\hline \multicolumn{1}{c|}{ Source } & \multicolumn{1}{c|}{ DF } & \multicolumn{1}{c|}{ SS } & \multicolumn{1}{c|}{ MS } & \multicolumn{1}{c}{ F } & \multicolumn{1}{c}{ P } \\
\hline Intensitas Cahaya & 2 & 1,02075 & 0,510377 & 3923,87 & 0,00 & \\
Jarak Kamera & 2 & 1,51626 & 0,758132 & 5828,65 & 0,00 & \\
Interaction & 4 & 0,02400 & 0,006001 & 46,13 & 0,00 \\
Error & 18 & 0,00234 & 0,000130 & & \\
Total & 26 & 2,56336 & & & \\
\hline
\end{tabular}

R Squared $=, 999($ Adjusted $\mathrm{R}$ Squared $=, 999)$

Pada Tabel 9, nilai $F$ tabel ( $\alpha$, df1, df2) yaitu $F$ tabel $(0,05,2,16)$ untuk faktor intensitas cahaya dan jarak kamera sebesar 3,63, sedangkan hasil pengolahan data diketahui bahwa nilai $\mathrm{F}$ hitung sebesar 18,569 untuk intensitas cahaya dan 176,870 untuk jarak kamera. Selain itu F tabel $(0,05$, $3,16)$ untuk interaksi sebesar 3,24 dan nilai $\mathrm{F}$ hitung sebesar 26,433 . Ini berarti nilai $\mathrm{F}$ hitung untuk semua faktor dan interaksi tersebut $>\mathrm{F}$ tabel atau nilai $\mathrm{P}$-value $<(\alpha=5 \%)$, maka keputusan yang dapat diambil adalah

Tabel 9 Analysis of Variance untuk Respon Tingkat Error Pada Pengukuran Dry Spots

\begin{tabular}{l|l|l|l|l|l}
\hline \multicolumn{1}{c|}{ Source } & \multicolumn{1}{c|}{ DF } & \multicolumn{1}{c|}{ SS } & \multicolumn{1}{c|}{ MS } & \multicolumn{1}{c}{ F } \\
\hline Intensitas Cahaya & 2 & 0,030 & 0,015 & 18,569 & 0,00 \\
Jarak Kamera & 2 & 0,289 & 0,144 & 176,870 & 0,00 \\
Interaction & 3 & 0,065 & 0,022 & 26,433 & 0,00 \\
Error & 16 & 0,013 & 0,001 & & \\
Total & 23 & 1,334 & & & \\
\hline
\end{tabular}

$\mathrm{R}$ Squared $=.968($ Adjusted $\mathrm{R}$ Squared $=.954)$

\section{Analisis Korelasi}

Analisis korelasi digunakan untuk mengukur kekuatan hubungan linier antara dua variabel. Koefisien korelasi populasi $\rho(r h o)$ adalah ukuran kekuatan hubungan linier antara dua variabel dalam populasi sedangkan koefisien korelasi sampel $r$ adalah estimasi dari $\rho$ dan digunakan untuk mengukur kekuatan hubungan linier dalam sampel observasi (Walpole dan Myers 1989). Berdasarkan Tabel 10 dan Tabel 11 dapat disimpulkan bahwa jarak kamera dengan tingkat error pengukuran luas ubin dan dry spots memiliki korelasi yang kuat dengan nilai koefisien korelasi >0,5.

menolak $\mathrm{H}_{0}$ ini berarti variabel intensitas cahaya dan jarak kamera maupun interaksi, secara keseluruhan mempunyai pengaruh yang signifikan terhadap respon tingkat error dari hasil pengukuran dry spots.

Tabel 9 juga menunjukkan bahwa kedua faktor dan interaksi faktor berpengaruh signifikan terhadap tingkat error pengukuran luas ubin, di mana semakin besar nilai $\mathrm{F}$ hitung menunjukkan semakin besar pula pengaruhnya, sehingga urutan pengaruhnya dari besar ke kecil adalah jarak kamera, interaksi kedua faktor, dan intensitas cahaya. 


\section{SIMPULAN}

Terdapat pengaruh yang signifikan faktor intensitas cahaya, jarak kamera serta interaksi kedua faktor (intensitas cahaya dan jarak kamera) terhadap persentase tingkat error pengukuran luas dan defect ubin keramik.Urutan faktor yang berpengaruh dari besar ke kecil untuk persentase tingkat error pengukuran luas ubin keramik yaitu jarak kamera, intensitas cahaya, dan interaksi kedua faktor (jarak kamera danintensitas), sedangkan untuk persentase tingkat error pengukuran diameter dry spots (defect) urutan faktor yang berpengaruh dari besar ke kecil yaitu jarak kamera, interaksi kedua faktor (jarak kamera dan intensitas cahaya), dan intensitas cahaya.

Tingkat errorterkecil dari pengukuran luas permukaan ubin diperoleh pada intensitas cahaya 300 lx dengan jarak $50 \mathrm{~cm}$ sebesar $0,0675 \%$. Untuk tingkat errorterkecil dari pengukuran diameter dry spots (defect) permukaan ubin diperoleh pada intensitas cahaya $300 \mathrm{~lx}$ dengan jarak $50 \mathrm{~cm}$ sebesar $2,30 \%$. Nilai threshold citra biner 0,5 dengan pengurangan brightness sebesar 5 , dengan kombinansi nilai grayscale untuk tingkat error pengukuran luas permukaan dan pengukuran diameter dry spots adalah 0,2989 x $\mathrm{R}+0,1140 \times \mathrm{G}+0,5870 \times \mathrm{B}$.

Berdasarkan korelasi antara intensitas cahaya, jarak kamera terhadap tingkat error pengukuran luas ubin, maka didapat nilai koefisien korelasi Jarak Kamera dengan Tingkat Error memiliki nilai 0,518 yang berarti korelasi sangat kuat. Sedangkan pengaruh terhadap pengukuran cacat $d r y$ spots diperoleh hubungan Jarak Kamera dengan Tingkat Error pengukuran dry spots memiliki nilai 0,516 yang berarti hubungan korelasi kuat.

\section{DAFTAR PUSTAKA}

Afandi, A. S., Prihandoko, dan Bertalya(2010) Klasifikasi Kualitas Keramik Menggunakan Metode Deteksi Tepi Laplacian of Gaussian dan Prewitt, Proceeding Seminar Ilmiah Nasional KOMMIT, 27.
Baroroh, D. K. (2014) Optimasi Proses Electrochemical Machining Pada Pembuatan Multilayered Microfilter Dengan Pendekatan Full Factorial Design, Tugas Akhir, Universitas Gadjah Mada.

Boukouvalas, C., Kittler, J., Marik, R., Mirmehdi, M., dan Petrou, M. (1998) Ceramic Tile Inspection for Color and Structural Defect, I.E.E.E Transactions on Pattern Analysis and Machine Vision Intelligence, Vol. 14, no. 1.

Elbehiery, H., Hefnawy, A., and Elewa, M. (2005) Surface Defects Detection for Ceramic Tiles Using Image Processing and Morphological Techniques, Proceedings of World Academy of Science, Engineering and Technology, vol 5, pp 158-160, April 2005, ISSN 1307-6884.

Jayabal, S., Natarajan, U., \& Sekar, U. (2011) Regression Modeling and Optimization of Machinability Behavior of Glass-Coir-Polyester Hybrid Composite Using Factorial Design Methodology, International Journal of Advanced Manufacturing Technology, no. 55, pp. 263-273.

Kadir, A., dan Susanto, A. (2013) Teori dan Aplikasi Pengolahan Citra, Penerbit ANDI Yogyakarta

Pratiwi, D., Putra, A. P., Sim, P. H., dan Kartowisastro, I. H. (2014) Segmentasi Objek di bawah Pengaruh Pencahayaan, Tugas Akhir, Universitas Bina Nusantara.

Rahman, G. M. A. and Hossain, Md. M. (2009) Automatic Defect Detection And Classification Technique From Image: A Special Case Using Ceramic Tiles, International Journal of Computer Science and Information Security, 1 (1).

Wise dkk.(1990)A Brief Introduction to Multivariate Image Analysis (MIA), Eigenvector Research, Inc., Umea University. 